IZA DP No. 2421

Does Equal Pay Legislation Reduce Labour Market Inequality?

Leo Kaas

November 2006 


\title{
Does Equal Pay Legislation Reduce Labour Market Inequality?
}

\author{
Leo Kaas \\ University of Konstanz \\ and IZA Bonn
}

Discussion Paper No. 2421

November 2006

\author{
IZA \\ P.O. Box 7240 \\ 53072 Bonn \\ Germany \\ Phone: +49-228-3894-0 \\ Fax: +49-228-3894-180 \\ E-mail: iza@iza.org
}

\begin{abstract}
Any opinions expressed here are those of the author(s) and not those of the institute. Research disseminated by IZA may include views on policy, but the institute itself takes no institutional policy positions.
\end{abstract}

The Institute for the Study of Labor (IZA) in Bonn is a local and virtual international research center and a place of communication between science, politics and business. IZA is an independent nonprofit company supported by Deutsche Post World Net. The center is associated with the University of Bonn and offers a stimulating research environment through its research networks, research support, and visitors and doctoral programs. IZA engages in (i) original and internationally competitive research in all fields of labor economics, (ii) development of policy concepts, and (iii) dissemination of research results and concepts to the interested public.

IZA Discussion Papers often represent preliminary work and are circulated to encourage discussion. Citation of such a paper should account for its provisional character. A revised version may be available directly from the author. 
IZA Discussion Paper No. 2421

November 2006

\section{ABSTRACT}

\section{Does Equal Pay Legislation Reduce Labour Market Inequality?*}

This paper considers a labour market model of monopsonistic competition with taste-based discrimination against minority workers to study the effect of equal pay legislation on labour market inequality. When the taste for discrimination is small or competition is weak, the policy removes job segregation and the wage gap completely. However, with a bigger taste for discrimination or stronger competition, equal pay legislation leads to more job segregation, and sometimes minority workers end up earning less than before. Profits of discriminating firms may increase, and discrimination can persist in the long run although it would have disappeared without the policy.

JEL Classification: D43, J71, J78

Keywords: discrimination, monopsonistic competition, equal pay legislation

Corresponding author:

Leo Kaas

Department of Economics

University of Konstanz

78457 Konstanz

Germany

E-mail: leo.kaas@uni-konstanz.de

* I am indebted to Paul Madden for many helpful discussions. I would also like to thank seminar participants in Bern, Bielefeld and Konstanz for their comments. 


\section{Introduction}

Wage differentials between different demographic groups are a prevalent phenomenon in most developed countries. In spite of powerful equal-pay legislation and other anti-discrimination measures, these gaps remain considerable, even after controlling for workers' qualification and experience. While wage differentials at the job cell level (occupation-establishment) are small, occupational segregation and establishment segregation are important causes of the wage gaps, and there is only weak tendency of segregation to decline. ${ }^{1}$ The aim of this paper is to demonstrate that equal-pay legislation can, by itself and under certain circumstances, increase job segregation, reduce wages of minority workers, and contribute to the persistence of discriminatory behaviour on the side of employers.

Economic theories of labour market discrimination can be divided into two strands. One is statistical discrimination in the presence of imperfect information (Phelps (1972) and Arrow (1973)), the other is taste-based discrimination where some agents have a distaste against interacting with minority workers (Becker (1957)). Such discrimination may occur on the side of employers, co-workers or customers. As Becker pointed out, taste-based employer discrimination can have no permanent effect on the wage gap in a competitive labour market. In the long run (i.e. under free entry or perfect capital mobility) there will be enough non-discriminatory employers who hire all minority workers at the same wage as majority workers. In a sense, segregation helps to reduce and eventually eliminate discrimination in the competitive model (see Cain (1986), p.711-712). In an imperfectly competitive labour market, however, such a result need not hold. First, monopsonists (and similarly monopsonistic competitors) may easily discriminate if labour supply elasticities differ between demographic groups (Robinson (1933)). Second, taste-based employer discrimination can persist in models of monopsonistic wage competition since discriminators earn positive profits and will not necessarily be forced out of

\footnotetext{
${ }^{1}$ For gender, see e.g. Petersen and Morgan (1995) and Carrington and Troske (1995) for the US and Meyersson Milgrom et al. (2001) for Sweden, and for race (US) see Bayard et al. (1999). Although race and ethnic segregation in the US declined between 1960 and 1980, this trend seems to have stopped since then (see Tomaskovic-Devey et al. (2005)).
} 
the market by non-discriminatory employers (Bhaskar et al. (2002)). Search models, as another departure from the competitive paradigm, also permit persistence of taste-based discrimination (Black (1995), Bowlus and Eckstein (2002), Lang et al. (2005)).

This paper develops a simple model of monopsonistic wage competition in the spirit of Salop (1979) and Bhaskar et al. (2002) in which some employers have a distaste for hiring minority workers.A crucial feature of the model is that employers can, in principle, discriminate both in pay and in hiring. Without any equal-pay legislation, employers only discriminate in pay but not in hiring. The wage gap is positive and is a consequence of both employment segregation and within-firm wage discrimination. The introduction of an equal-pay legislation can have very different effects on labour market inequality, depending on the structural model parameters. When the taste for discrimination is small or when competition between employers is weak, the policy is successful in completely eliminating segregation and the wage gap: although discriminators pay lower wages than non-discriminators, all employers hire majority and minority workers in the same proportion. However, in the opposite case of stronger competition or stronger discriminatory tastes, the policy is not successful in removing inequality. Discriminatory employers, who are not allowed to discriminate in pay, decide to discriminate in hiring by rejecting minority job applicants. Whenever this happens, non-discriminatory employers face a relatively inelastic labour supply of minority workers and are thus inclined to lower their wage. In the end, the labour market becomes more segregated, and sometimes both minority and majority workers earn less than under the laissez-faire benchmark. Furthermore, employer discrimination can become more likely to persist with the equal-pay legislation: even when discriminatory behaviour is eliminated under laissez-faire in the long run, this may not be true under the equal-pay legislation.

In this model, there is no trade-off between equality and efficiency: whenever the economy ends up in the "good" equilibrium with zero wage gap and without segregation, the policy is also welfare-enhancing. But when a "bad" equilibrium with more segregation and a positive wage gap is achieved, welfare is lower than under laissez faire. Finally, the model also shows that a larger share of minority workers leads 
to more segregation and a bigger wage gap. This is consistent with the evidence that there is more black-white segregation and wage inequality in local labour markets with a larger black population in the US (see Huffman and Cohen (2004) and references therein). Intuitively, a larger share of white workers spurs competition between discriminating and non-discriminating employers, raises wages and reduces inter-firm wage differentials.

Crucial for the model is the assumption that firms are allowed to discriminate in hiring. This seems to be at odds with labour market legislation in most countries which not only prohibit discrimination in pay but also in employment opportunities, including hiring. ${ }^{2}$ However, particularly hiring discrimination is hard to monitor and to punish in practice. Private firms can easily decide not to invite certain minority applicants for a job interview without being accused of discrimination. While affirmative action may help to reduce hiring discrimination, such measures are only applied to a small section of the labour market (typically public employers or government contractors). Strict employment quotas, on the other hand, are considered illegal in most countries. ${ }^{3}$ In fact there is considerable evidence of hiring discrimination from natural experiments (Goldin and Rouse (2000)), from audit studies (Neumark et al. (1996))) or from field experiments using correspondence testing (Bertrand and Mullainathan (2004)); see also the surveys in Darity and Mason (1998) and Altonji and Blank (1999).

The remainder of the paper is organized as follows. The next section introduces the model framework, and Section 3 discusses the laissez faire equilibrium. Section 4 shows how the firms' wage policies respond to the introduction of equal-pay legislation. Section 5 analyzes the different equilibria that can emerge under equal-pay legislation. Sections 6 and 7 discuss efficiency and the persistence of discrimination,

\footnotetext{
${ }^{2}$ In the US, this is formulated in title VII of the Civil Rights Act of 1964 and enforced by the Equal Employment Opportunity Commission (EEOC), established in 1965.

${ }^{3}$ In the US, all firms with more than 100 employees are required to submit detailed employment numbers to the EEOC who is authorized to initiate lawsuits on the basis of underrepresentation of women and minorities in the workforce. However, such lawsuits are rare (Holzer and Neumark (2000)), and firms who want to discriminate against some group (e.g. black males) can easily circumvent the EEOC requirements by hiring more members of another protected group (e.g. white females). For evidence on this last issue, see Bisping and Fain (2000).
} 
and Section 8 concludes.

\section{The model}

Consider a local labour market which is modelled as a circular city of unit length in the spirit of Salop (1979) and Bhaskar et al. (2002). The city is populated by two uniformly distributed groups of workers, each supplying one unit of indivisible labour. There is a mass $\mu$ of majority workers who are termed "white" and a mass 1 of minority workers who are termed "black" . $\mu$ may be any strictly positive number; if it is less than one, the number of minority workers exceeds the one of majority workers in the local labour market. Principally, the model can also be interpreted as one of gender discrimination. In this case, $\mu$ should reflect the participation rate of men relative to women in the local labour market. There are three firms, located symmetrically on the circle. Firm 0 has a taste for discrimination, and firms 1 and 2 are colour-blind.

All workers are equally productive at all firms and their reservation wages are independent of membership in the two demographic groups. In particular, the marginal product of labour at any firms is constant at $A$, and each worker must pay transportation costs $t x^{2}$ in order to travel distance $x$ to work. ${ }^{4}$ In another interpretation, these costs may also reflect the workers' preferences over horizontally differentiated non-wage job characteristics. The transportation cost parameter $t$ naturally corresponds to the degree of competition in this model: lower values of $t$ make jobs at the three firms closer substitutes which leads to fiercer wage competition.

While firms 1 and 2 are conventional profit maximizers, firm 0 has a taste for discrimination: it derives disutility $d>0$ for each black worker in its workforce. The objective function of firm 0 is assumed to be profits minus disutility from black employment. It is assumed throughout the paper that $A$ is large relative to both $d$ and $t$. This makes sure that all workers want to work for any of the three firms at equilibrium wages and that firm 0 wants to hire black workers at a sufficiently low

\footnotetext{
${ }^{4}$ Quadratic, rather than linear, transportation costs are assumed in order to avoid the wellknown payoff discontinuities coming from "hinterland effects".
} 
wage. In particular, I deliberately abstract from any (adverse) employment effects of equal-treatment policy. ${ }^{5}$

All workers have a zero reservation wage and are interested in maximizing wage income net of transportation costs. The strategic interaction between firms and workers is modeled by the following three-stage wage-posting game:

Stage I: Firms simultaneously announce wages $w_{i}^{s}, i \in\{0,1,2\}, s=W, B$.

Stage II: Workers send out applications.

Stage III: Firms make offers to applicants. Workers with more than one offer pick the one that is best for them. Firms' eventual employment of white and black workers is denoted $L_{i}^{s}, i \in\{0,1,2\}, s=W, B$.

Subsequent sections consider equilibria of this game under laissez-faire and under an equal-pay legislation. Under laissez-faire, firms are free to pay different wages to the two groups. Equal-pay legislation restricts such discriminatory behaviour by forcing firms to announce the same wage $w_{i}=w_{i}^{B}=w_{i}^{W}, i \in\{0,1,2\}$, to the two groups. What the policy cannot do, however, is to prevent firms from discrimination in hiring at the third stage of the game. In particular, the discriminating firm 0 may decide to reject black applicants at the hiring stage. As has been argued in the introduction, such equal opportunity in hiring is difficult, if not impossible to enforce by law, and there is strong evidence of hiring discrimination, in spite of a long tradition of equal-opportunity enforcement.

Stages II and III can be solved easily. At stage II, a worker of type $s \in\{B, W\}$ located distance $x$ from firm $i$ will apply at $i$ whenever $w_{i}^{s}-t x^{2} \geq 0$. At stage III, firms 1 and 2 make offers to all applicants of type $s$ provided that $A-w_{i}^{s}>0$,

\footnotetext{
${ }^{5}$ This model with three firms, two of them being colour-blind, is the simplest environment in which there is proper wage competition, even when discriminators reject black applicants. The assumptions also guarantee that the limit $t \rightarrow 0$ corresponds to the perfectly competitive benchmark which would not be true if there was only one colour-blind firm. A tedious extension to $n$ firms, one of them being a discriminator, should be possible using the techniques of Bhaskar and To (2003).
} 
$i=1,2$. Firm 0 makes offers to all white applicants if $A-w_{0}^{W}>0$ and it makes offers to all black applicants if $A-d-w_{0}^{B}>0$, rejecting all black applicants if $A-d-w_{0}^{B}<0$. A worker of type $s$ who has more than one offer will accept the one where wage minus transportation cost is highest. The assumption that $A$ is large relative to $t$ guarantees that there is no unemployment at equilibrium wages so that $L_{0}^{W}+L_{1}^{W}+L_{2}^{W}=\mu$ and $L_{0}^{B}+L_{1}^{B}+L_{2}^{B}=1$.

Subsequent sections study the effects of equal-pay legislation on the following two measures of labour market inequality. The wage gap is the difference between the average white wage and the average black wage. Given full employment of all workers, this is

$$
G \equiv \frac{1}{\mu} \sum_{i=0}^{2} w_{i}^{W} L_{i}^{W}-\sum_{i=0}^{2} w_{i}^{B} L_{i}^{B} .
$$

Further, employment segregation is measured by the Duncan segregation index (Duncan and Duncan (1955)) which is defined as the fraction of black (or white) workers that would need to change employment so as to have equal black-white ratios at both firms. Again given full employment and using the observation that employment levels at the symmetric firms 1 and 2 are identical in any equilibrium, the segregation index is

$$
S \equiv\left|L_{0}^{B}-L_{0}^{W} / \mu\right|=2\left|L_{1}^{B}-L_{1}^{W} / \mu\right|=2\left|L_{2}^{B}-L_{2}^{W} / \mu\right|
$$

The extreme cases are $S=0$ (no segregation) and $S=1$ (perfect segregation).

\section{The laissez-faire equilibrium}

Suppose that firms can discriminate in their wages offered to the two demographic groups. Payoffs are

$$
\begin{aligned}
& \pi_{0}=\left(A-w_{0}^{W}\right) L_{0}^{W}+\left(A-d-w_{0}^{B}\right) L_{0}^{B}, \\
& \pi_{i}=\left(A-w_{i}^{W}\right) L_{i}^{W}+\left(A-w_{i}^{B}\right) L_{i}^{B}, i=1,2 .
\end{aligned}
$$

Clearly, no firm will offer a wage above marginal product, and firm 0 will not offer a wage to blacks above $A-d$. Provided that wages are high enough and close to 
each other, group-specific labour supply to any firm is

$$
L_{i}^{s}=\frac{1}{3}+\frac{3}{t}\left(w_{i}^{s}-\frac{w_{i+1}^{s}+w_{i-1}^{s}}{2}\right), i \in\{0,1,2\}, s=B, W,
$$

with the usual modulo 3 notation. Because of payoff separability, stage I wage competition can be solved separately for white and for black workers. Wage competition for white workers leads to the symmetric solution

$$
w_{i}^{W}=A-\frac{t}{9} \quad, \quad L_{i}^{W}=\frac{\mu}{3}, i \in\{0,1,2\} .
$$

Competition for black workers leads to an asymmetric allocation of workers because of 0 's preference for discrimination. Provided that $d / t<5 / 18$, both firms hire black workers:

$$
\begin{aligned}
& w_{0}^{B}=A-\frac{t}{9}-\frac{3 d}{5}<w_{1}^{B}=w_{2}^{B}=A-\frac{t}{9}-\frac{d}{5} \\
& 0<L_{0}^{B}=\frac{1}{3}-\frac{6 d}{5 t}<L_{1}^{B}=L_{2}^{B}=\frac{1}{3}+\frac{3 d}{5 t}<\frac{1}{2}
\end{aligned}
$$

When $d / t \geq 5 / 18$, however, firm 0 is squeezed out of the market for black workers. Black labour supply to firms 1 and 2 is

$$
L_{i}^{B}=\frac{1}{2}+\frac{9}{4 t}\left(w_{i}^{B}-w_{j}^{B}\right), i \neq j \in\{1,2\}
$$

provided that firm 0 gets zero share of black workers which happens under

$$
w_{1}^{B}+w_{2}^{B} \geq 2 w_{0}^{B}+\frac{2 t}{9}
$$

The best response of firms 1 and 2 to $w_{0}^{B}=A-d$ is $w_{1}^{B}=w_{2}^{B}=A-d+t / 9$ whenever $d \in[5 / 18,1 / 3]$ (so that (3) binds) and $w_{1}^{B}=w_{2}^{B}=A-2 t / 9$ whenever $d / t>1 / 3$ (and (3) is slack). It is also straightforward to show that $w_{0}^{B}=A-d$ is indeed a best response for firm 0 to these wages at 1 and 2 . Hence, for any $d / t \geq 5 / 18$, laissez-faire equilibrium in the market for black workers is

$$
\begin{gathered}
w_{0}^{B}=A-d<w_{1}^{B}=w_{2}^{B}=\min \left(A-d+\frac{t}{9}, A-\frac{2 t}{9}\right) \\
L_{0}^{B}=0 \quad, \quad L_{1}^{B}=L_{2}^{B}=1 / 2 .
\end{gathered}
$$

Summarizing these findings and calculating wage gap and segregation index yields

Proposition 1: The laissez-faire equilibrium is as follows: 
(a) If $d / t<5 / 18$, wages and employment levels are as in (1) and (2). The wage gap is $G=\frac{d}{3}-\frac{12 d^{2}}{25 t}<t / 18$ and the segregation index is $S=\frac{6 d}{5 t}<1 / 3$.

(b) If $d / t \geq 5 / 18$, wages and employment levels are as in (1) and (4). The wage gap is $G=\min (d-2 t / 9, t / 9)$ and the segregation index is $S=1 / 3$.

The following features are worth mentioning. First, black workers earn less than white workers at any of the three firms; that is, all firms discriminate in pay although only firm 0 has a taste for discrimination. Second, there is employment segregation, but the segregation index is never bigger than $1 / 3$ because firms share the white workforce equally. At most one third of workers of either colour would have to change employment to have a black-white employment ratio of $1 / \mu$ at all firms. The black-white wage gap is partly due to segregation between firms and partly due to wage discrimination within firms. Finally, it is straightforward to see that the wage gap disappears in the competitive limit $t \rightarrow 0$ since all workers earn their marginal product $A$, while segregation stays at $1 / 3$. As mentioned in the introduction, segregation eliminates discrimination in the competitive model.

\section{Wage policy under equal-pay legislation}

Suppose now that firms are not allowed to wage discriminate so that each firm must offer the same wage to all workers. To understand how the equilibrium set looks like, one has to study the best response behaviour of the two firms at the wage setting stage. How does each firm's wage policy depend on the wages of competitors?

Consider firm 0 first. The hiring decision at stage III depends critically on the level of $w_{0}$ : if $w_{0}<A-d$, firm 0 hires black and white workers in the same proportion as firms 1 and 2. Firm 0's payoff (profit minus disutility), assuming that $w_{2}=w_{1}$, is

$$
\pi_{0}=\left(A-\frac{d}{1+\mu}-w_{0}\right)(1+\mu)\left(\frac{1}{3}+\frac{3}{t}\left(w_{0}-w_{1}\right)\right) .
$$

Conversely, if $w_{0}>A-d$ firm 0 rejects all black workers at stage III, hiring only white workers. Its payoff is then

$$
\pi_{0}=\left(A-w_{0}\right) \mu\left(\frac{1}{3}+\frac{3}{t}\left(w_{0}-w_{1}\right)\right) .
$$


Comparing (5) and (6) shows that payoff is continuous in $w_{0}$ and kinks upwards at $w_{0}=A-d$ (where firm 0 is indifferent between hiring black workers or not). Therefore, $w_{0}=A-d$ cannot be a best-response to any $w_{1}=w_{2}$. Instead, there is a critical level of $w_{1}=w_{2}=\tilde{w}$ such that 0 's best response $w_{0}=R_{0}\left(w_{1}\right)$ is nondiscriminatory $\left(w_{0}<A-d\right)$ when $w_{1}=w_{2}<\tilde{w}$ and discriminatory $\left(w_{0}>A-d\right)$ when $w_{1}=w_{2}>\tilde{w}$. In other words, the best response curve of firm 0 jumps upwards at $w_{1}=w_{2}=\tilde{w}$.

What is best response behaviour of firms 1 and 2? When $w_{0}<A-d$, firm 0 does not reject black applicants at stage III, so that firms 1 and 2 compete with 0 for white and black workers. Firm 1 obtains profit

$$
\pi_{1}=\left(A-w_{1}\right)(1+\mu)\left(\frac{1}{3}+\frac{3}{t}\left(w_{1}-\frac{w_{0}+w_{2}}{2}\right)\right),
$$

provided that $w_{1}+w_{2} \leq 2 w_{0}+2 t / 9$ (so that firm 0 is not squeezed out of the market). When $w_{0}>A-d$, firm 0 rejects all black applicants at stage III. Thus, black labour supply to firm 1 becomes more inelastic in $w_{1}$, and firm 1's profit is

$$
\left.\pi_{1}=\left(A-w_{1}\right)\left(\frac{1}{2}+\frac{9}{4 t}\left(w_{1}-w_{2}\right)+\frac{\mu}{3}+\frac{3 \mu}{t}\left(w_{1}-\frac{w_{0}+w_{2}}{2}\right)\right)\right) .
$$

This shows that firm 1's profit is discontinuous in $w_{0}$, jumping up when $w_{0}$ increases beyond $A-d$. Combining the best responses of both firms 1 and 2 to the wage at firm 0 shows that the reaction function $w_{1}=w_{2}=R_{1}\left(w_{0}\right)$ jumps down at $w_{0}=A-d$ : as $w_{0}$ increases beyond $A-d$, firms 1 and 2 suddenly face a more inelastic supply of labour, so they cut their wage.

In summary, firm 0's best response function jumps up (at $w_{1}=w_{2}=\tilde{w}$ ), and the symmetric best response of 1 and 2 jumps down (at $w_{0}=A-d$ ). Because of these jumps in best-response functions, there is an open (albeit small) set of parameter configurations for which no equilibrium in pure strategies exists. The following section concentrates on those situations that permit existence of (at least one) pure-strategy equilibrium.

\section{Equilibrium under equal-pay legislation}

There are two types of pure-strategy equilibria: 
(N) No-discrimination equilibrium. Here $w_{1}=w_{2}>w_{0}$ and $w_{0}<A-d$, there is no segregation and the wage gap is zero $(G=S=0)$.

(H) Equilibrium with hiring discrimination where $w_{1}=w_{2}<w_{0}$ and $w_{0}>A-d$, $L_{1}^{B}=L_{2}^{B}=1 / 2, L_{0}^{B}=0, L_{0}^{W}>L_{1}^{W}=L_{2}^{W}$. Segregation is larger than under laissez-faire $(S>1 / 3)$ and the wage gap is positive.

The following discussion establishes necessary and sufficient conditions for these equilibria to exist.

\subsection{No discrimination}

In an equilibrium without hiring discrimination $\left(w_{0}<A-d\right)$, firm 0 maximizes (5), firm 1 maximizes (7) and firm 2 solves a problem analogous to firm 1. Solving these problems yields wages

$$
w_{0}^{*}=A-\frac{t}{9}-\frac{3 d}{5(1+\mu)}<w_{1}^{*}=w_{2}^{*}=A-\frac{t}{9}-\frac{d}{5(1+\mu)} .
$$

As has been shown above, firm 0's payoff is non-concave at $w_{0}=A-d$. To make sure that $w_{0}^{*}$ is indeed a best response one needs that $w_{0}^{*}<A-d$ and that 0 does not want to deviate to some $w_{0}>A-d$. As is shown in the proof of Proposition 2, a necessary and sufficient condition for these two requirements is

$$
\frac{d}{t} \leq \delta_{N}(\mu) \equiv \frac{10(1+\mu)}{9} \cdot \frac{\sqrt{1+\mu}-\sqrt{\mu}}{4 \sqrt{1+\mu}+\sqrt{\mu}}
$$

Firm 1's payoff function (7) applies only when firms 1 and 2 do not capture firm 0's market, i.e. when $w_{1}+w_{2}<2 w_{0}+2 t / 9$ holds. But this condition is easily verified at equilibrium wages (9) under condition ( $\mathrm{N})$. Moreover, $\pi_{1}$ is also concave in $w_{1}$ outside this range (it kinks down at $w_{1}=2 w_{0}^{*}-w_{2}^{*}+2 t / 9$ ), hence $w_{1}^{*}$ is indeed a best response to $w_{0}^{*}$ and $w_{2}^{*}=w_{1}^{*}$. Both firms employ positive shares of black and white workers, each in the same proportion:

$$
L_{0}^{B *}=\frac{L_{0}^{W *}}{\mu}=\frac{1}{3}-\frac{6 d}{5(1+\mu) t}<L_{i}^{B *}=\frac{L_{i}^{W *}}{\mu}=\frac{1-L_{0}^{B *}}{2}, i=1,2 .
$$


Proposition 2: There exists a no-discrimination equilibrium with wages (9) and employment levels (10) if, and only if, condition (N) is satisfied.

Proof: Appendix.

Consequently, when the taste for discrimination is small enough or when competition between firms is weak enough, equal-pay legislation succeeds in removing discrimination completely. As should be expected, the average white wage falls and the average black wage increases relative to laissez faire.

\subsection{Hiring discrimination}

Now consider an equilibrium with $w_{0}>A-d$ where 0 rejects all black applicants. In this situation, firm 0 maximizes payoff (6), firm 1 maximizes profit (8), and firm 2 solves a similar problem. Solving these problems yields equilibrium wages

$$
w_{0}^{*}=A-\frac{t}{9} \frac{9+10 \mu}{6+10 \mu}>w_{1}^{*}=w_{2}^{*}=A-\frac{t}{9} \frac{6+5 \mu}{3+5 \mu},
$$

and employment of white workers

$$
L_{0}^{W *}=\frac{\mu}{3}+\frac{\mu}{6+10 \mu}>L_{1}^{W *}=L_{2}^{W *}=\frac{\mu}{3}-\frac{\mu}{12+20 \mu}>0 .
$$

To support this equilibrium, one needs that $w_{0}^{*}>A-d$ and that 0 does not want to deviate to $w_{0}<A-d$. As before, these requirements follow from a single condition that is derived in the proof of Proposition 3:

$$
\frac{d}{t} \geq \delta_{H}(\mu) \equiv \frac{9+10 \mu}{9(3+5 \mu)}(1+\mu-\sqrt{\mu(1+\mu)}) .
$$

Hence $(\mathrm{H})$ guarantees that $w_{0}^{*}>A-d$ is a best response to $w_{1}^{*}$. On the other hand, it is also shown in the proof of Proposition 3 that firm 1 (and similarly firm 2) does not deviate to a wage $w_{1}<\left(w_{0}^{*}+w_{2}^{*}\right) / 2-t / 9$ where it only employs black workers. ${ }^{6}$

\footnotetext{
${ }^{6}$ This is not obvious since firm 1's profit has an upward kink at this point. One can also show that there is no equilibrium with complete segregation where firm 0 hires all white workers and firms 1 and 2 share the black workforce equally. Indeed, if there was such an equilibrium, firm 1 would set its wage just high enough to attract all white workers, i.e. $w_{0}=w_{1}+2 t / 9$, but at this point firm 1's profit has an upward kink in $w_{1}$, so $w_{1}=w_{0}-2 t / 9$ cannot be a best response to $w_{0}$ and $w_{2}=w_{1}$.
} 
Proposition 3: There exists an equilibrium with hiring discrimination with wages (11), white employment (12) and black employment $L_{1}^{B}=L_{2}^{B}=1 / 2$ if, and only if, condition $(\mathrm{H})$ is satisfied. The wage gap is $G=(9+10 \mu) t /\left(36(3+5 \mu)^{2}\right)$ and the segregation index is $S=1 / 3+1 /(6+10 \mu)$.

Proof: Appendix.

When the taste for discrimination is large or when competition is strong, equal-pay legislation does not remove labour market inequality and there is more segregation than under laissez-faire. White workers always lose under the policy, and one can also show that the wage gap falls relative to laissez-faire. However, black workers do not always gain under the policy: sometimes the average black wage falls as well. ${ }^{7}$

Corollary: Suppose condition (H) is satisfied.

(a) The introduction of equal - pay legislation raises segregation and lowers the racial wage gap. The average wage for black workers sometimes falls.

(b) Labour market inequality, as measured by $S$ and $G$, is falling in the share of white workers in the labour market.

\section{Proof: Appendix.}

Part (b) says that local labour markets with a larger black population have more racial inequality, consistent with the evidence for the USA. Intuitively, when there are more black workers, labour supply to the non-discriminating firms 1 and 2 becomes more inelastic, and this pushes their wages down relative to the one at firm 0 (who hires relatively more white workers).

Figure 1 illustrates which parameters lead to equilibria with and without discrimination. The Figure shows that there are no multiple pure-strategy equilibria (i.e. $\delta_{N}(\mu)<\delta_{H}(\mu)$ for all $\mu$ ), and that there is a (small) range of parameter values for which there is no equilibrium in pure strategies. The Figure also shows the range

\footnotetext{
${ }^{7}$ Because of more segregation, total surplus for black workers (wage income net of total transportation costs) also falls when their average wage falls.
} 
of parameters where the average black wage is lower than under laissez-faire (area $\mathrm{H} 1)$. This outcome requires a predominantly black population $(\mu<1)$ together with a moderate taste for discrimination relative to the degree of competition.

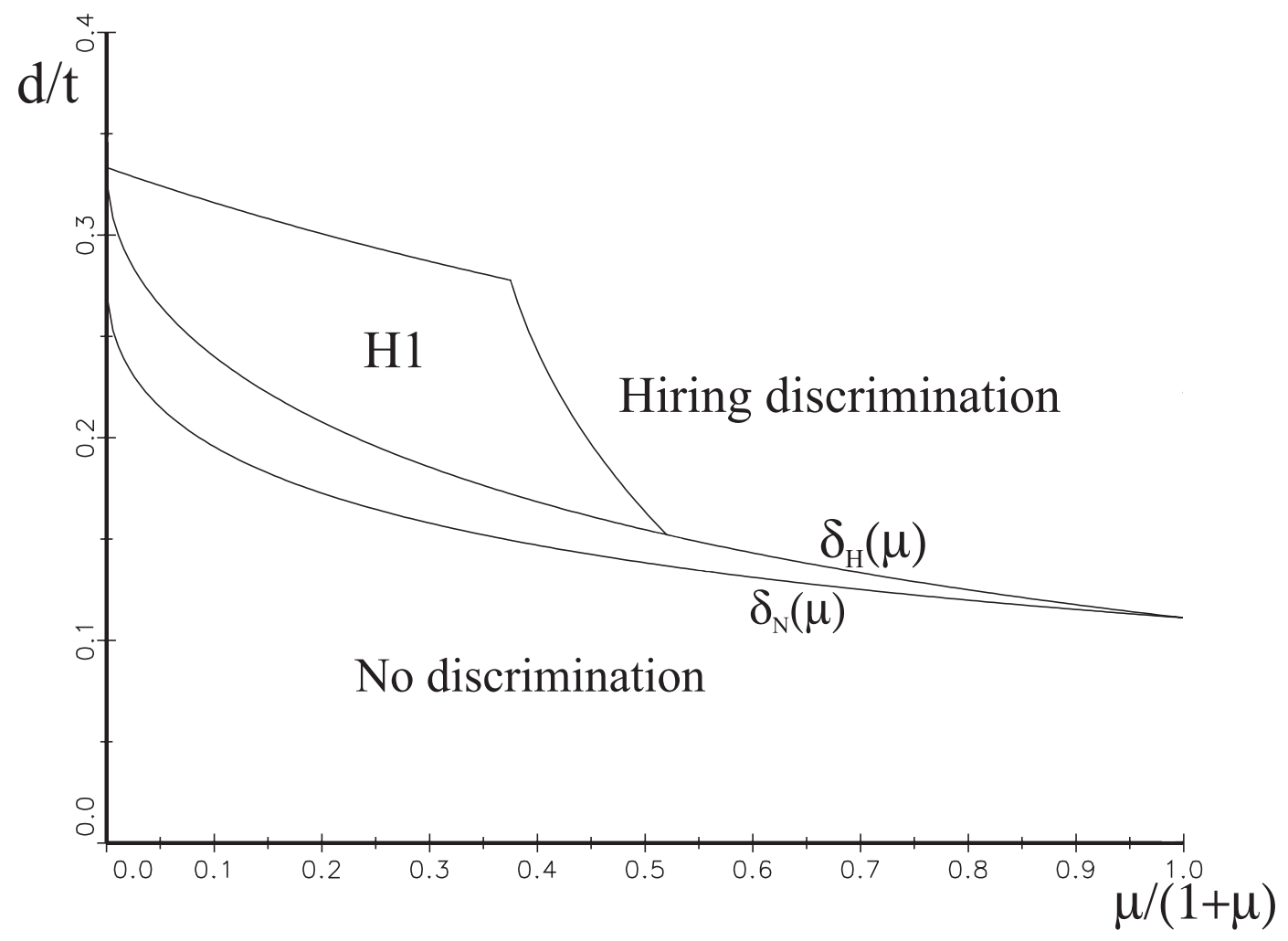

Figure 1: Equilibrium types depending on $d / t$ and on the relative share of white workers, $\mu /(1+\mu)$. Area H1 shows parameters where the mean black wage falls under the policy.

\section{Social welfare}

Propositions 2 and 3 show how differently the policy can affect labour market inequality: sometimes inequality (in segregation and in pay) is removed, but sometimes inequality does not disappear. One may wonder how the policy performs with respect to efficiency. Is there a trade-off between equality and efficiency in this model? 
The general answer to this question is "no": welfare goes up whenever inequality is removed, but it falls when inequality survives.

Social welfare is measured by the total surplus in the labour market which is defined as total output minus total transportation costs. Obviously, this number is the same as the sum of workers' net incomes (wages minus transportation costs) and firms' profits. The welfare measure does not include the taste for discrimination which is considered to be a preference disturbance of management that is not in the objective interest of firm owners. The potential conflict between discriminatory management and firm owners is discussed in the next section.

Because all workers are employed and produce the same output in any equilibrium, total output does not change under the policy. In other words, welfare increases if, and only if, total transportation costs fall.

Under laissez faire and $d / t \leq 5 / 18$, total transportation costs are

$$
\begin{aligned}
T_{L F} & \equiv(6 \mu+2) \int_{0}^{\frac{1}{6}} t x^{2} d x+2 \int_{0}^{\frac{1}{6}-\frac{3 d}{5 t}} t x^{2} d x+2 \int_{0}^{\frac{1}{6}+\frac{3 d}{5 t}} t x^{2} d x \\
& =(1+\mu) \frac{t}{108}+\frac{6 d^{2}}{25 t} .
\end{aligned}
$$

The first term in the first line are travel costs of white workers and of those black workers living between firms 1 and 2. The second term are travel costs of black workers working for firm 0 while the third term are travel costs of black workers living between 0 and 1 or 2 who do not work for firm 0 . For $d / t>5 / 18$, a similar calculation yields

$$
T_{L F}=(1+\mu) \frac{t}{108}+\frac{t}{54}
$$

Under equal pay legislation, and if $d / t \leq \delta_{N}(\mu)$, there is an equilibrium without discrimination, the employment share of firm 0 is $L_{0}=1 / 3-6 d /(6 t(1+\mu))$, and so transportation costs are

$$
\begin{aligned}
T_{N} & \equiv 2(1+\mu)\left(\int_{0}^{\frac{1}{6}} t x^{2} d x+\int_{0}^{\frac{1}{6}-\frac{3 d}{5(1+\mu)}} t x^{2} d x+\int_{0}^{\frac{1}{6}+\frac{3 d}{5(1+\mu)}} t x^{2} d x\right) \\
& =(1+\mu) \frac{t}{108}+\frac{6 d^{2}}{25 t(1+\mu)} .
\end{aligned}
$$

Because $d / t \leq \delta_{N}(\mu) \leq 5 / 18$, comparison of (13) and (14) reveals that transportation costs are higher under laissez-faire than in the no-discrimination equilibrium. 
Therefore, welfare always increases under the policy if the policy is successful in removing inequality. Nevertheless, welfare is still below the social optimum which would require the three firms to share the workforce equally.

In an equilibrium with hiring discrimination, in contrast, welfare falls since transportation costs

$$
\begin{aligned}
T_{H} & \equiv(2+2 \mu) \int_{0}^{\frac{1}{6}} t x^{2} d x+2 \int_{0}^{\frac{1}{3}} t x^{2} d x+2 \mu \int_{0}^{\frac{1}{6}-\frac{1}{12+20 \mu}} t x^{2} d x+2 \mu \int_{0}^{\frac{1}{6}+\frac{1}{12+20 \mu}} t x^{2} d x \\
& =(1+\mu) \frac{t}{108}+\frac{t}{54}+\frac{2 t \mu}{3(12+20 \mu)^{2}}
\end{aligned}
$$

are bigger than under laissez faire. Thus,

Proposition 4: The introduction of equal pay legislation raises social welfare in any no-discrimination equilibrium, but it lowers social welfare in every equilibrium with hiring discrimination.

\section{Persistence of discrimination}

Gary Becker has argued that the wage gap is zero in a competitive labour market in the long run: discriminators do not hire minority workers and wage competition between non-discriminators makes sure that minority and majority workers earn the same wages. Obviously, matters are different under imperfect competition. Nevertheless, under laissez faire firm 0's profit is lower than the one at firms 1 and 2. So a natural question emerges whether it is in the interest of the owner of firm 0 (who is only interested in the value of the firm) to replace a discriminatory management by a non-discriminatory one so as to raise profits. ${ }^{8}$ Thus, augment the three stage game by a preceding stage ("the long run") at which firm 0's owner considers to replace the discriminatory management by one which is neutral with respect to race (or gender). Discrimination persists whenever the owner does not exercise this option which is the case whenever firm 0's profit with $d>0$ is no less than firm 0's

\footnotetext{
${ }^{8}$ Alternatively, if firm 0 is owned by a discriminatory owner-manager, the firm will be taken over by a non-discriminatory owner whenever profits (and thereby firm value) can be raised by the change of ownership.
} 
profit with $d=0$. More generally, one may also consider the decisions of owners of firms 1 and 2 whether or not to engage a discriminatory management instead of a neutral one. However, since these firms make higher profit than firm 0 , such a change in management is not as likely to be exercised as it may be at firm 0 . To keep the analysis as simple as possible, only firm 0's owner considers a management replacement prior to the wage setting stage.

In the laissez-faire equilibrium of Proposition 1, firm 0's profit is (when $d / t \leq 5 / 18$ )

$$
\pi_{0}^{L F}=(1+\mu) \frac{t}{27}+\frac{d}{15}-\frac{18 d^{2}}{25 t}
$$

By engaging a non-discriminatory management, firm 0 would obtain profit

$$
\hat{\pi}_{0} \equiv(1+\mu) \frac{t}{27}
$$

Thus, firm 0's owner does not exercise this option if, and only if, $d / t \leq 5 / 54$. In other words, discrimination persists under laissez faire when $d / t \leq 5 / 54$, but it disappears in the long run otherwise. A discriminatory management pays lower wages to black workers but it also hires a smaller number of them and produces less output. At low values of $d / t$ the profitable "wage effect" dominates the costly "employment effect". That is, firm 0's profit is higher with a discriminatory management. ${ }^{9}$ The opposite is the case at higher values of $d / t$. Alternatively phrased, discrimination disappears without any policy intervention when the labour market is very competitive, in line with Gary Becker's reasoning.

What happens if equal-pay legislation is introduced? Surprisingly, it turns out that firm 0 will not always change its management, even when it would do so under laissez faire. If there is a no-discrimination equilibrium, firm 0's profit is

$$
\pi_{0}^{N}=(1+\mu) \frac{t}{27}+\frac{d}{15}-\frac{18 d^{2}}{25 t(1+\mu)}
$$

while a change of management would again yield $\hat{\pi}_{0} . \quad \pi_{0}^{N}$ is larger than $\pi_{0}$ if $d / t \leq 5(1+\mu) / 54$. Hence, for any $d / t \leq \delta_{N}(\mu)$ and $d / t \in[5 / 54,5(1+\mu) / 54]$,

\footnotetext{
${ }^{9}$ This result seems puzzling since discriminators do not maximize profits. From the perspective of the owner, however, the adoption of a discriminatory management is a "commitment device" against fierce (and unprofitable) wage competition.
} 
discriminatory behaviour becomes more persistent under the equal-pay policy than under laissez-faire. In both cases, inequality disappears in the long run: if the policy is in place, firm 0 simply stops discriminating in pay and in hiring without a management change, but without the policy the discriminatory management is replaced by the firm owner. Nevertheless, welfare is lower with the policy since the wage and employment differential between the firms does not disappear. Hence, there is a long-run welfare loss of the policy.

Can an equilibrium with hiring discrimination persist? Firm 0's profit can be calculated as

$$
\pi_{0}^{H}=\frac{\mu t}{27}\left(\frac{9+10 \mu}{6+10 \mu}\right)^{2}
$$

and one can demonstrate that this expression is always smaller than $\hat{\pi}_{0}$. Therefore, discriminatory behaviour can never persist in an equilibrium with hiring discrimination. Hence, inequality disappears in the long run. However, since $d / t \geq \delta_{H}(\mu)>$ $5 / 54$, inequality would also have disappeared without any policy intervention, with the same long-run effect on social welfare.

\section{Proposition 5:}

(a) In the long run, the black-white wage gap and the segregation index are zero under equal-pay legislation for all combinations of $(d / t, \mu)$, while they are positive under laissez faire if $d / t \leq 5 / 54$.

(b) If $d / t \in[5 / 54,5(1+\mu) / 54]$ and $d / t \leq \delta_{N}(\mu)$, equal-pay legislation entails a welfare loss in the long run relative to the laissez faire outcome, because a discriminatory management is retained under the policy but not under laissez faire.

\section{Conclusion}

This paper considers a model of a monopsonistically competitive labour market with taste-based employer discrimination. It is shown that equal-pay legislation can have 
a very different impact, depending on the strength of discriminatory taste and on the degree of competition.

- If the taste for discrimination is modest and if competition is weak, equal-pay policy succeeds in removing wage inequality and job segregation. The policy is also welfare enhancing in the short run. Sometimes, however, discriminatory behaviour may become more persistent so that the policy entails a welfare loss relative to laissez faire in the long run.

- In contrast, if discriminatory tastes are more pronounced and if competition is stronger, equal-pay legislation leads to more job segregation and sometimes to lower wages for minority workers. The policy proves to be welfare deteriorating in the short run, but in the long run all inequality must disappear, as would also be the case under laissez faire.

I expect that these policy conclusions extend to more general full-employment environments with an arbitrary number of firms. When the full-employment assumption (a large enough labour productivity) is dropped, however, there is room for additional, and potentially quite different effects. In particular, when discriminators reject black applicants and when transportation costs are large relative to labour productivity, it may happen that non-discriminators do not employ all minority workers so that some of them are unemployed. Thus it may well happen that equalpay legislation entails also adverse employment effects for minority workers. These extensions are left for future research.

\section{Appendix}

\section{Proof of Proposition 2:}

The first requirement $w_{0}^{*}<A-d$ is equivalent to

$$
\frac{d}{t}<\frac{5(1+\mu)}{9(2+5 \mu)}
$$


Straightforward algebra shows that this condition follows from (N). If firm 0 deviates to $w_{0}>A-d$ it would obtain payoff (6) which attains its maximum

$$
\tilde{\pi}_{0}=\frac{3 \mu}{t}\left(\frac{t}{9}+\frac{d}{10(1+\mu)}\right)^{2}
$$

at

$$
\tilde{w}_{0}=A-\frac{t}{9}-\frac{d}{10(1+\mu)} .
$$

Such a deviation is not profitable if either $\tilde{w}_{0} \leq A-d$ (in which case $\pi_{0}$ is decreasing in $\left.w_{0} \geq A-d\right)$ or if $\tilde{\pi}_{0}<\pi_{0}^{*}$ where

$$
\pi_{0}^{*}=\frac{3(1+\mu)}{t}\left(\frac{t}{9}-\frac{2 d}{5(1+\mu)}\right)^{2}
$$

is firm 0's profit at $w_{0}^{*}$. The second condition is the same as $(\mathrm{N})$ and the first condition is

$$
\frac{d}{t}<\frac{10(1+\mu)}{9(9+10 \mu)}
$$

A little algebra reveals that this condition is stronger than $(\mathrm{N})$ so that $(\mathrm{N})$ is necessary and sufficient to preclude deviations to $w_{0}>A-d$.

\section{Proof of Proposition 3:}

First, one needs to show that $w_{0}^{*}>A-d$ which is the same as

$$
\frac{d}{t}>\frac{9+10 \mu}{9(6+10 \mu)}
$$

Straightforward algebra shows that this is a consequence of $(\mathrm{H})$. If firm 0 deviates to $w_{0}<A-d$ it obtains payoff (5) which attains maximum

$$
\tilde{\pi}_{0}=\frac{3(1+\mu)}{4 t}\left(\frac{t(9+10 \mu)}{9(3+5 \mu)}-\frac{d}{1+\mu}\right)^{2}
$$

at

$$
\tilde{w}_{0}=A-\frac{t(9+10 \mu)}{18(3+5 \mu)}-\frac{d}{2(1+\mu)} .
$$

To ensure that such a deviation does not happen, one needs either $\tilde{\pi}_{0} \leq \pi_{0}$ where

$$
\pi_{0}^{*}=\frac{3 \mu}{4 t}\left(\frac{t(9+10 \mu)}{9(3+5 \mu)}\right)^{2}
$$


is payoff at $w_{0}^{*}$, or $\tilde{w}_{0} \geq A-d$. The first condition is $(\mathrm{H})$ and the second condition is

$$
\frac{d}{t} \geq \frac{(1+\mu)(9+10 \mu)}{9(1+2 \mu)(3+5 \mu)}
$$

which is stronger than $(\mathrm{H})$. Thus, $(\mathrm{H})$ is necessary and sufficient to ensure that firm 0 does not deviate from $w_{0}^{*}>A-d$.

Finally, it is to show that firm 1 does not deviate to a wage below $\hat{w}_{1} \equiv\left(w_{0}^{*}+\right.$ $\left.w_{2}^{*}\right) / 2-t / 9$ where firm 1 stops attracting white workers. When 1 attracts only black workers, its profit is

$$
\tilde{\pi}_{1}=\left(A-w_{1}\right)\left(\frac{1}{2}+\frac{9}{4 t}\left(w_{1}-w_{2}^{*}\right)\right)
$$

which is concave in $w_{1}$ and maximal at

$$
\tilde{w}_{1}=A-\frac{t(12+15 \mu)}{9(6+10 \mu)}
$$

One can easily verify, however, that $\tilde{w}_{1}>\hat{w}_{1}$. Hence, $\tilde{\pi}_{1}$ is strictly increasing in $w_{1} \leq \hat{w}_{1}$, so that $w_{1}^{*}>\hat{w}_{1}$ is indeed a best response to $w_{0}^{*}$ and $w_{2}^{*}$.

\section{Proof of the Corollary:}

(a) Because the segregation index in Proposition 3 is larger than $1 / 3$, it is also bigger than under laissez faire. When $d / t \leq 5 / 18$, the wage gap falls relative to laissez faire iff

$$
\frac{\delta}{3}-\frac{12 \delta^{2}}{25}>\frac{9+10 \mu}{36(3+5 \mu)^{2}}
$$

where $\delta \equiv d / t$. Since the left-hand side is increasing in $\delta \leq 5 / 18$, the inequality holds for all $\delta \geq \delta_{H}(\mu)$ iff it holds at $\delta_{H}(\mu)$. But this is the same as

$$
1<\frac{4 c(\mu)}{3}(3+5 \mu-4(9+10 \mu) c(\mu) / 25)
$$

with $c(\mu) \equiv 1+\mu-\sqrt{\mu(1+\mu)} \in[.5,1]$, which is true for all $\mu \geq 0$. For $\delta \geq 5 / 18$, the laissez-faire wage gap is at least as large as the left-hand side of (16), so that (16) still holds.

The mean black wage never falls under the policy when $d / t \geq 1 / 3$. For $\delta \leq 5 / 18$, the mean black wage under laissez faire is $A-t / 9-d / 3+12 d^{2} /(25 t)$. This wage is 
larger than the mean black wage with the policy under $(\mathrm{H})\left(w_{1}^{*}\right.$ in Proposition 3) iff

$$
\delta-\frac{36}{25} \delta^{2}<\frac{1}{3+5 \mu}
$$

One can verify that this condition is compatible with $\delta \geq \delta_{H}(\mu)$ (see area H1 in Figure 1$)$. When $\delta \in(5 / 18,1 / 3)$, the mean black wage under laissez-faire is $A-$ $d+t / 9$, which is larger than $w_{1}^{*}$ iff

$$
\delta<\frac{9+10 \mu}{9(3+5 \mu)}
$$

which is again compatible with $\delta \geq \delta_{H}(\mu)$ (area H1 in Figure 1 again). Part (b) is obvious.

\section{References}

Altonji, J., And R. Blank (1999): "Race and Gender in the Labor Market," in Handbook of Labor Economics, ed. by O. Ashenfelter, and D. Card, vol. 3, chap. 48. North-Holland, Amsterdam.

Arrow, K. (1973): "The Theory of Discrimination," in Discrimination in Labor Markets, ed. by O. Ashenfelter, and A. Rees. Princeton University Press, Princeton, NJ.

Bayard, K., J. Hellerstein, D. Neumark, and K. Troske (1999): "Why are Racial and Ethnic Wage Gaps Larger for Men Than for Women? Exploring the Role of Segregation Using the New Worker-Establishment Characteristics Database," Working Paper 6997, National Bureau of Economic Research.

Becker, G. (1957): The Economics of Discrimination. University of Chicago Press, Chicago.

Bertrand, M., and S. Mullainathan (2004): "Are Emily and Greg More Employable Than Lakisha and Jamal? A Field Experiment on Labor Market Discrimination," American Economic Review, 94, 991-1013. 
Bhaskar, V., A. Manning, and T. To (2002): "Oligopsony and Monopsonistic Competition in Labor Markets," Journal of Economic Perspectives, 16, 155-174.

Bhaskar, V., And T. To (2003): "Oligopsony and the Distribution of Wages," European Economic Review, 47, 371-399.

Bisping, T., And J. FAIn (2000): "Job Queues, Discrimination, and Affirmative Action," Economic Inquiry, 38, 123-135.

BlaCK, D. (1995): "Discrimination in an Equilibrium Search Model," Journal of Labor Economics, 13, 309-334.

Bowlus, A., And Z. ECKSTEIN (2002): "Discrimination and Skill Differences in an Equilibrium Search Model," International Economic Review, 43, 1309-1345.

CAIn, G. (1986): "The Economic Analysis of Labor Market Discrimination: A Survey," in Handbook of Labor Economics, ed. by O. Ashenfelter, and R. Layard, vol. 1, chap. 13. North-Holland, Amsterdam.

Carrington, W., and K. Troske (1995): "Gender Segregation in Small Firms," Journal of Human Resources, 30, 503-533.

DARITY, W., AND P. MAson (1998): "Evidence on Discrimination in Employment: Codes of Color, Codes of Gender," Journal of Economic Perspectives, 12, 63-90.

Duncan, O., And B. Duncan (1955): "A Methodological Analysis of Segregation Indexes," American Sociological Review, 20, 200-217.

Goldin, C., And C. Rouse (2000): "Orchestrating Impartiality: The Impact of Blind Auditions on Female Musicians," American Economic Review, 90, 715-741.

Holzer, H., And D. Neumark (2000): “Assessing Affirmative Action," Journal of Economic Literature, 38, 483-568.

Huffman, M., And P. Cohen (2004): "Racial Wage Inequality: Job Segregation and Devaluation across U.S. Labor Markets," American Journal of Sociology, 109, 902-936. 
Lang, K., M. Manove, and W. Dickens (2005): "Racial Discrimination in Labor Markets with Posted Wage Offers," American Economic Review, 95, 13271340.

Meyersson Milgrom, E., T. Petersen, and V. Snartland (2001): "Equal Pay for Equal Work? Evidence from Sweden and a Comparison with Norway and the U.S.," Scandinavian Journal of Economics, 103, 559-583.

Neumark, D., R. Bank, and K. Van Nort (1996): "Sex Discrimination in Restaurant Hiring: An Audit Study," Quarterly Journal of Economics, 111, 915941.

Petersen, T., And L. Morgan (1995): "Separate and Unequal: OccupationEstablishment Sex Segregation and the Gender Wage Gap," American Journal of Sociology, 101, 329-365.

Phelps, E. (1972): "The Statistical Theory of Racism and Sexism," American Economic Review, 62, 659-661.

Robinson, J. (1933): The Economics of Imperfect Competition. Macmillan, London.

SAlOP, S. (1979): "Monopolistic Competition with Outside Goods," Bell Journal of Economics, 10, 141-156.

Tomaskovic-Devey, D., C. Zimmer, C. Robinson, T. Taylor, T. MCTague, K. Stainback, and J. Wolf (2005): "Documenting Desegregation: Estimates of US Workplace Sex and Ethnic Segregation 1966-2000," Working Paper, North Carolina State University. 